\title{
SINOPSE DO GÊNERO LISSONOSCHEMA (COLEOPTERA, CERAMBYCIDAE, CERAMBYCINAE, TRACHYDERINI) ${ }^{1}$
}

\author{
Marcela L. Monné \\ Miguel A. Monné 3
}

\begin{abstract}
SYNOPSIS OF THE GENUS LISSONOSCHEMA (COLEOPTERA, CERAMBYCIDAE, CERAMBYCINAE, TRACHYDERINI). The genus Lissonoschema Martins \& Monné is redefined and $L$. solangeae sp. nov. is described from Brazil (Mato Grosso). A key to the three species is added.

KEYWORDS. Cerambycidae, Cerambycinae, Lissonoschema, Taxonomy, Trachyderini.

\section{INTRODUÇÃO}

O gênero Lissonoschema, restrito à América do Sul, foi proposto por MARTins \& Monné (1978) para duas espécies: Lissonoschema macrocolum Martins \& Monné, 1978, do Espírito Santo (Brasil) e para Lissonotypus fasciatus Fisher, 1944, da Venezuela, transferida para Lissonoschema. Apresentamos a redescrição do gênero, chave de identificação para as espécies e a descrição de Lissonoschema solangeae sp. nov., proveniente do Mato Grosso (Brasil).

O material estudado pertence ao Museu Nacional, Universidade Federal do Rio de Janeiro, Rio de Janeiro (MNRJ).
\end{abstract}

1. Contribuição n 1174 do Departamento de Zoologia, Universidade Federal do Paraná.

2. Departamento de Zoologia, Universidade Federal do Paraná; Caixa Postal 19020; CEP 81531-990 Curitiba, PR, Brasil. (Bolsista CAPES)

3. Museu Nacional, Universidade Federal do Rio de Janeiro; Quinta da Boa Vista; CEP 22940-040 Rio de Janeiro, RJ, Brasil. (Bolsista CNPq) 


\section{Lissonoschema Martins \& Monné, 1978}

Lissonoschema Martins \& Monné, 1978:65, fig.1; Fragoso, Monné \& Seabra, 1987:200; Monné, 1994:105; MonNÉ \& GIESBERT, 1994:146; 1995:150.

Espécie-tipo: Lissonoschema macrocolum Martins \& Monné, 1978 por designação original.

Todo corpo com superfície lisa e brilhante. Cabeça com raros pontos finos e rasos; região posterior com estrias finas e transversais. Fronte profundamente escavada. Tubérculos anteníferos aguçados no ápice. Vértice com depressão rasa. Submento densamente pontuado e com pêlos densos, curtos e eretos. Genas subtriangulares, divergentes, com pontos finos, esparsos e rasos; tão longas quanto a metade do diâmetro do lobo ocular inferior. Lobos superiores dos olhos com carena no lado interno. Mandíbulas com 2/3 basais esparsa e grosseiramente pontuadas; ápices lisos e bífidos. Antenas com evidente dimorfismo sexual; nos machos, filiformes ou subserreadas e com doze antenômeros; nas fêmeas, serreadas e com onze antenômeros. Escapo (figs. 1, 3, 5, 7) cilíndrico, curto, robusto e encurvado; pedicelo curto e transverso; antenômero III (figs. $1,5,7)$ cerca de três vezes o comprimento do escapo, carenado e com projeção obtusa nos ápices interno e externo; antenômeros III-XII (XI nas fêmeas) com pilosidade curta e densa, exceto o ápice interno liso e brilhante, superfície microesculturada e pontos finos e densos. Nos machos, as antenas alcançam o ápice elitral nos antenômeros V ou VI; IVXI subiguais, antenômero XII (figs. 2, 6) variável. Nas fêmeas, alcançam o ápice elitral no antenômero IX; IV-X decrescem gradualmente e XI (fig. 4) abruptamente estreitado no 1/3 distal. Protórax tão longo quanto largo ou mais longo que largo; nos lados com ou sem gibosidades. Margens anterior e posterior estreitadas. Pronoto convexo. Processo prosternal cerca de 1/3 do diâmetro de uma procoxa; vertical no ápice. Cavidades cotilóides anteriores abertas atrás. Mesosterno deprimido no meio. Processo mesosternal cerca de 2/3 do diâmetro de uma mesocoxa com a margem apical bilobada. Cavidades cotilóides médias fechadas lateralmente. Metasterno convexo, cerca de 2/3 do comprimento do prosterno. Mesepimero com pilosidade curta e esparsa. Escutelo cordiforme. Élitros cerca de 2,0 a 2,5 vezes o comprimento do protórax, pouco mais largos que o protórax na base, com os lados ligeiramente estreitados para os ápices. Superfície com raros pontos finos e rasos. Região externa do friso sutural, ao lado do escutelo, profunda e longitudinalmente deprimida. Extremidades elitrais arredondadas. Úmeros pouco proeminentes, arredondados. Pernas anteriores e posteriores subiguais e 1/3 mais longas que as medianas. Coxas arredondadas, com pontos finos e densos e pubescência densa e esbranquiçada. Fêmures pedunculado-clavados; os posteriores apenas ultrapassam os ápices dos élitros; meso- e metafêmures com espinho apical interno cerca da metade da largura do ápice do fêmur, subiguais. Tíbias médias e posteriores carenadas no lado externo. Tarsos curtos, primeiro metatarsômero mais curto que os dois seguintes reunidos; escovas tarsais compactas. Urosternito III uma vez e meia mais longo que o seguinte. Último urosternito com margem apical arredondada ou truncada.

Discussão. MARTINS \& Monné (1978) consideraram Lissonoschema próximo à Lissonotypus. Lissonoschema difere de Lissonotypus, principalmente por: fronte profundamente escavada; lobos superiores dos olhos com carena no lado interno; 
antenômero III carenado e cerca de 3 vezes o comprimento do escapo; protórax tão longo quanto largo ou mais longo que largo; extremidades elitrais arredondadas; pernas anteriores e posteriores com comprimento subigual. Em Lissonotypus a fronte não apresenta escavações, a guarnição interna dos lobos superiores dos olhos é pouco elevada, o antenômero III é sulcado e cerca de 1,5 vezes o comprimento do escapo, o protórax é mais largo que longo, as extremidades elitrais são subtruncadas ou angulosas na sutura e as pernas anteriores com cerca de $2 / 3$ do comprimento das posteriores.

Chave para as espécies de Lissonoschema.

1. Protórax e élitros castanho-escuros; élitros com faixa transversal mediana amarela; mesepisterno liso; machos com último urosternito arredondado na margem apical. Venezuela, Suriname L. fasciatum (Fisher, 1944)

Protórax de outra cor; élitros pretos com a região circumescutelar vermelha; mesepisterno com pontos densos, rasos e finos; machos com último urosternito truncado na margem apical 2

2(1). Cabeça, escapo, pedicelo, protórax e aos lados dos élitros, na metade anterior, vermelhos; lados do protórax, na metade posterior, com gibosidades proeminentes; antenômero XII, nos machos, (fig. 6) curto, achatado, expandido nos $2 / 3$ anteriores, no $1 / 3$ distal estreitado, aguçado e recurvo no ápice, cerca da metade do III (figs. 5, 8) Brasil (Mato Grosso) ............. L. solangeae sp. nov.

Cabeça, escapo, pedicelo, protórax e lados dos élitros, pretos; lados do protórax sem gibosidades; antenômero XII, nos machos, (fig. 2) longo, filiforme, estreitado para o ápice e este recurvo, cerca de 3/4 do III (fig. 1). Brasil (Espírito Santo).. L. macrocolum Martins \& Monné, 1978

\section{Lissonoschema solangeae sp. nov.}

(Figs. 5, 6, 8)

Etimologia. Homenagem à Dra. Dilma Solange Napp, por sua valiosa contribuição ao conhecimento de Cerambycidae.

o. Cabeça, escapo, pedicelo, protórax, élitros, na região circumescutelar e nos lados, da metade anterior e fêmures, vermelhos; antenômeros III-XII, élitros, tíbias e tarsos, pretos; mesosterno, metasterno e abdome, castanho-avermelhados. Antenômeros III-XII com pubescência curta, densa e preta; IV-XII achatados e subserreados; antenômero XII (fig. 6) expandido nos $2 / 3$ anteriores, no $1 / 3$ distal estreitado e aguçado e recurvo no ápice, cerca da metade do III (fig. 5) e subigual ao IV e X. Protórax (fig. 8) tão largo quanto longo com os lados, na metade posterior, com gibosidades proeminentes. Prosterno sem pontuação sexual. Processo prosternal com pontos finos e rasos, adensados para o ápice. Mesosterno e metepisterno lisos e glabros. Mesepisterno com densos pontos rasos e finos e pêlos curtos, densos e amarelados. Metasterno com pontos finos, rasos e esparsos e pêlos curtos, esparsos e amarelados. Élitros (fig. 8) cerca de 2,0 vezes o comprimento 


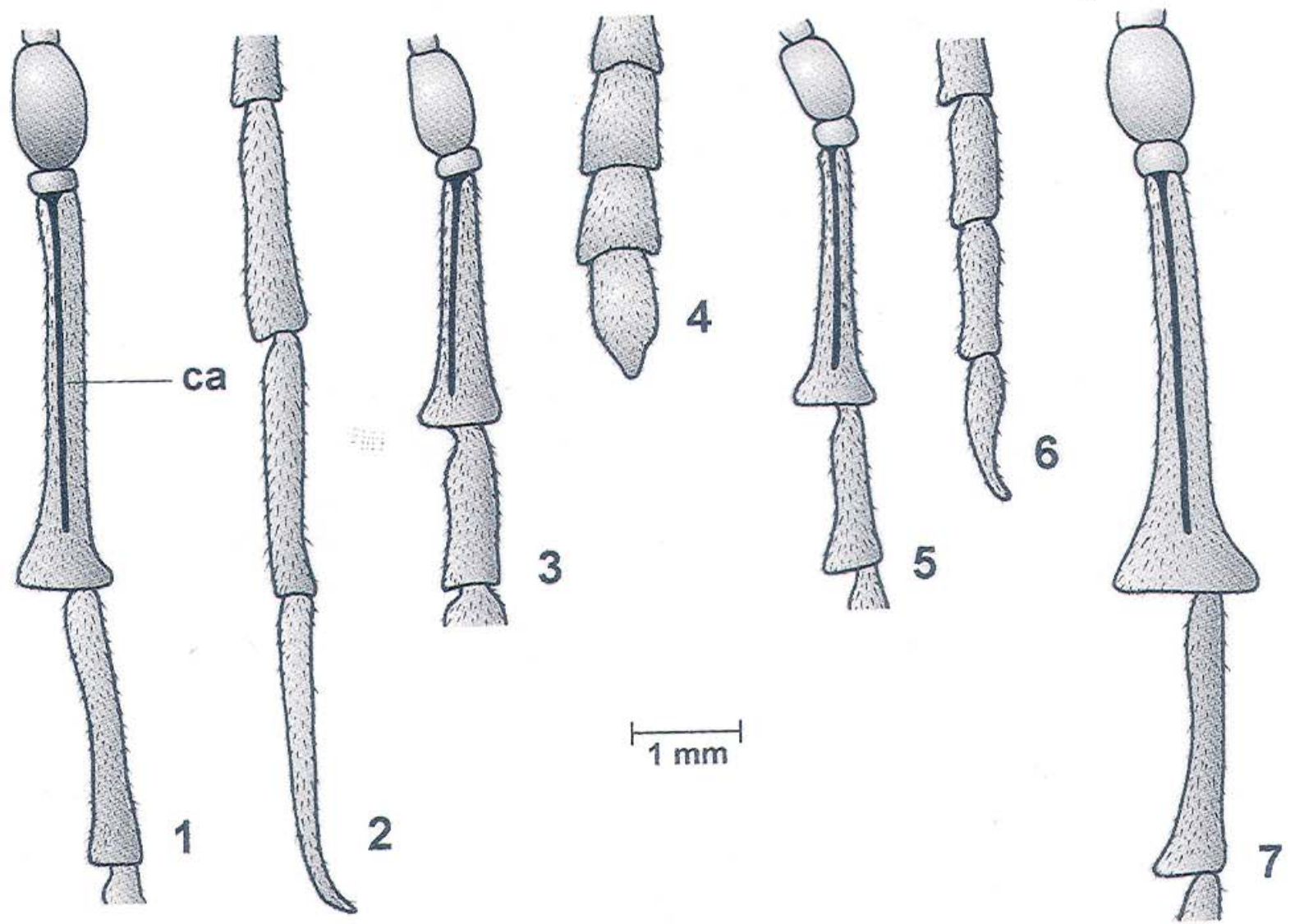

Higs. 1-1. Antenomeros basais e apicais: 1,2, Lissonoschema macrocolum Martins \& Monne, holotipo o; 3, 4, parátipo, ㅇ; 5, 6, L. solangeae sp. nov., holótipo ơ; 7, L. fasciatum (Fisher), ठ' (ca=carena).

do protórax. Abdome com pilosidade amarelada, curta e decumbente em toda superfície. Último urosternito com a margem apical truncada.

Dimensões, mm, ơ. Comprimento total 8,8; comprimento do protórax 2,5; maior largura do protórax 2,4; comprimento do élitro 5,0; largura umeral 3,0.

Material-tipo. BRASIL, Mato Grosso: Sinop, holótipo o’, X. 1976, Roppa \& Alvarenga col. (MNRJ).

Discussão. Lissonoschema solangeae (fig. 8) difere de L. macrocolum, por: cabeça, escapo, pedicelo, protórax e no lados dos élitros, na metade anterior, vermelhos; lados do protórax, na metade posterior, com gibosidades proeminentes; antenômero XII, nos machos, curto, achatado, expandido nos $2 / 3$ anteriores, no 1/3 distal estreitado, aguçado e recurvo no ápice, cerca da metade do III; mesosterno liso e glabro. Em L. macrocolum a cabeça, o escapo, o pedicelo, o protórax e os lados dos élitros, são pretos, os lados do protórax sem gibosidades, o antenômero XII, nos machos, longo, filiforme, estreitado para o ápice e este recurvo e cerca de $3 / 4$ do III e o mesosterno é densamente pontuado e ornado com pêlos curtos, densos e amarelados. L. fasciatum difere dessas espécies, além da coloração do corpo, pela pontuação sexual fina e adensada em duas pequenas áreas aos lados do prosterno. 


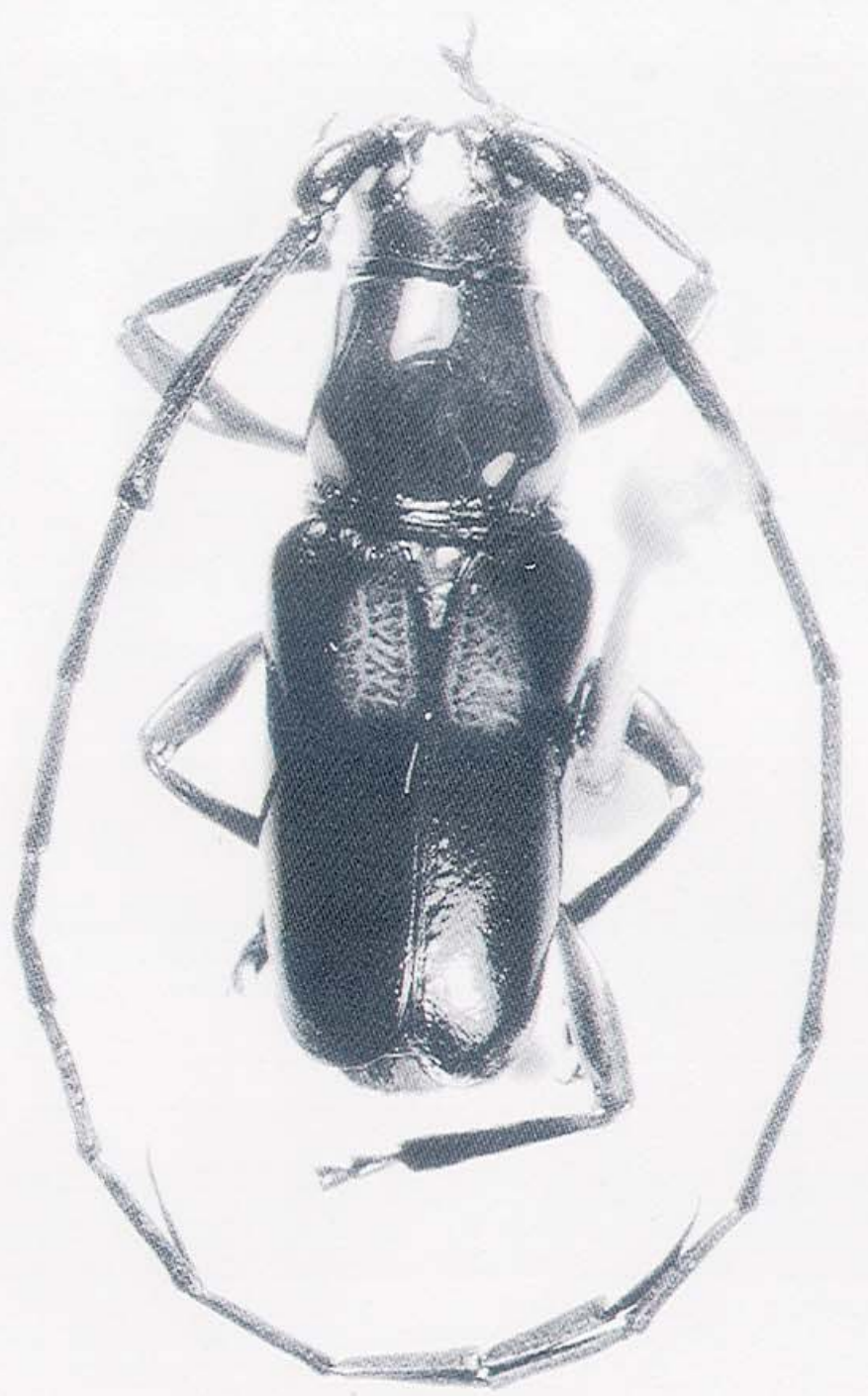

Fig. 8. Lissonoschema solangeae, sp. nov., holótipo ơ, comprimento, $8,8 \mathrm{~mm}$.

Agradecimentos. Ao Prof. Dr. Albino M. Sakakibara pela fotografia.

\section{REFERÊNCIAS BIBLIOGRÁFICAS}

Fragoso, S. A.; Monné, M. A. \& Seabra, C. A. C. 1987. Preliminary considerations on the higher classification of Cerambycinae (Coleoptera, Cerambycidae) with nomenclatural alterations. Revta bras. Biol., Rio de Janeiro, 47(1-2):189-202.

Martins, U. R. \& Monné, M. A. 1978. Notas e descrições em Lissonotini (Coleoptera, Cerambycidae). Revta bras. Ent., São Paulo, 22(2):65-68.

Monné, M. A. 1994. Catalogue of the Cerambycidae (Coleoptera) of the Western Hemisphere. Part XI. São Paulo, Sociedade Brasileira de Entomologia. 157 p.

Monné, M. A. \& Giesbert, E. F. 1994. Checklist of the Cerambycidae and Disteniidae (Coleoptera) of the Western Hemisphere. California, Wolsfgarden Books. 409 p.

1995. Checklist of the Cerambycidae and Disteniidae (Coleoptera) of the Western Hemisphere. California, Wolfsgarden Books. 419 p.

Recebido em 15.10.1999; aceito em 21.12.1999. 